\title{
Scapulothoracic dissociation and blunt vertebral vascular injury: case report
}

\section{Disociación escapulo-torácica y trauma cerrado de arteria vertebral: reporte de un caso}

\author{
Neil Valentin Vega Peña ${ }^{1}$ Manuel Riveros Dueñas ${ }^{1}$ Angie Carolina Riscanevo $^{1}$ \\ neilvalentin@gmail.com \\ Department of General Surgery, Clínica Reina Sofía, Colsanitas, Bogotá, Colombia
}

\section{Abstract}

\section{Case Description:}

A 24-year-old male suffers from a motor vehicle accident with penetrating neck trauma and concomitant closed left cervicothoracic trauma.

\section{Clinical Findings:}

High impact trauma causing hypovolemic shock, left zone I penetrating neck trauma, ischemia due to blunt trauma to the axillary vessels, and brachial plexus injury. Transection of the vertebral artery on angiotomography. Diagnosed with scapulothoracic dissociation and vertebral artery trauma.

\section{Treatment and outcome:}

Axillary arteriovenous reconstruction, fasciotomies, non-surgical approach of the vertebral artery trauma, and deferred treatment of the brachial plexus trauma were performed. Survival of the patient and his limb, with major neurologic sequelae

\section{Clinical Relevance:}

The case presented here is an example of scapulothoracic dissociation with associated trauma to the vertebral artery, injuries that are uncommon and associated with high morbidity and mortality. Early recognition of the injuries and a multidisciplinary approach for this complex case by surgical board reviews at various levels within the course of care were key determinants in the patient's improved prognosis. This case report presents an analysis of the diagnostics, treatment, and course; considering in-hospital care and the decision-making process as determinants for the prognosis in a polytrauma patient. 
Neil Valentin Vega Peña, Department of General Surgery, Clínica Reina Sofía, Colsanitas, Bogotá, Colombia. Mail:

neilvalentin@gmail.com

\section{Resumen}

\section{Descripción del caso:}

Varón de 24 años que sufre accidente automovilístico con trauma penetrante de cuello y trauma cerrado cervico torácico izquierdo concomitante.

\section{Hallazgos clínicos:}

Shock hipovolémico, trauma en zona I cuello izquierdo, isquemia por trauma cerrado de vasos axilares y lesión por trauma cerrado del plexo braquial; producto de trauma de alto impacto. Sección de arteria vertebral por angiotomografia. Se diagnostica disociación escapulo-torácica y trauma de arteria vertebral.

\section{Tratamiento y resultado:}

Reconstrucción vascular arterio-venosa axilar, fasciotomías y abordaje no operatorio del trauma de arteria vertebral, con manejo diferido del trauma del plexo braquial. Sobrevida del paciente y su extremidad, con secuelas neurológicas mayores.

\section{Relevancia clínica:}

Es un caso de disociación escapulotorácica y lesión de arteria vertebral concomitante, siendo esta una asociación infrecuente y de alta morbi-mortalidad. El reconocimiento temprano de las lesiones y un abordaje multidisciplinario de este escenario de complejidad por medio de juntas quirúrgicas en varios niveles del proceso de atención, fueron determinantes para cambiar el pronóstico del paciente. Se presenta un análisis del diagnóstico, manejo y evolución; considerando el proceso de atención hospitalaria, toma consensuada de decisiones y el pronóstico en un paciente politraumatizado.

\section{Introduction}

Scapulothoracic dissociation is a traumatic injury of the shoulder. The scapulothoracic joint is made up of the acromio-clavicular joint, glenohumeral joint, clavicle, scapula, and sternoclavicular joint. This type of injury can cause subclavian and axillary vascular injuries, partial or complete avulsion of the brachial plexus, and edema to the surrounding soft tissues ${ }^{1}$. It is an uncommon injury with a mortality rate up to $10 \%$ and caused by motor vehicle accidents in $44 \%$ of cases. Above the elbow amputation has been noted to be in around $20 \%$ of cases due to low potential for neurological recovery ${ }^{1-3}$.

The mechanism of injury is explained by the application of high energy traumatic forces, usually caused by high velocity mechanisms. Its management is challenging in all phases of care for the compromised patient ${ }^{1}$.

Blunt trauma to the vertebral artery is a rare entity with an incidence of $0.24 \%$ to $2.0 \%$ in cervical ${ }^{4}$, trauma cases and a mortality rate between $20-40 \%$, which has decreased due to early diagnosis and identification of lesion characteristics ${ }^{5}$.

This case report presents an unusual case of a patient where these two entities converge. We analyze the main points of intervention and decision-making that were effective in the management of the patient ${ }^{6}$. 


\section{Case presentation}

A 24-year-old male with no comorbidities presents due to a motorcycle accident that occured 20 minutes ago. At presentation, his vital signs are as follows: Glasgow 14/15 (confusion), BP: 85/45 mm Hg; MAP: 58 mm Hg; RR:22 respirations/minute, HR:130 beats/minute. Physical exam findings of a left transverse penetrating cervical trauma to zone I, left cervicothoracic edema and ecchymosis, left clavicle deformity, left upper extremity deformity with associated pulselessness, anesthesia, paralysis, and areflexia throughout. (Figure 1A).

The initial diagnosis was hypovolemic shock due to left zone I penetrating neck trauma, blunt trauma to the left axillary and subclavian vessels, and secondary neurovascular injury. Resuscitation was initiated with lactated ringers and oxygen therapy; packed red blood cells were reserved for the patient. Angiotomography was performed and reported a complete transection of the left axillary artery and vein in the distal third portion, ipsilateral scapular fracture, C4-C7 completely displaced transverse process fractures with compromise to the vertebral foramen and injury to the left vertebral artery. (Figure $1 \mathrm{C}$ and D)

The patient was taken into the operating room for surgical exploration of the penetrating neck injury where the left external jugular vein was localized and ligated in the setting of a partial transection. Infra-clavicular approach was used to drain 2,000 $\mathrm{mL}$ from a contained hematoma between the pectoralis and deltoid muscles, a complete transection of the axillary artery and vein were identified at its first segments, and avulsion of the humeral veins and secondary trunks of the brachial plexus were identified (Figure $2 \mathrm{E}$ ). At the intraoperative medical board with orthopedics, it was decided to continue with conservative management for the brachial plexus injury and a possible deferred neurological reconstruction was evaluated. For the time being, we performed an arterio-venous vascular reconstruction of the axillary vessels with internal saphenous vein grafting. The graft patency was confirmed with distal flow present on echo-Doppler intraoperatively and arteriography after surgery (Figure 2F). A concomitant bicompartmental fasciotomy of the forearm and Velpeau-type immobilization of the scapular fracture were also performed.

Post-operatively the patient was transferred to the intensive care unit. Cervical spine and spinal cord MRI angiography and head CT showed a lesion in segments V1 and V2 of the left vertebral artery without signs of dissection, a spinal hematoma, and cerebral edema without ischemic lesions. A medical board of neurosurgery and interventional neuroradiology decided for conservative management to limit distal thrombosis of the vertebral artery using anticoagulation of unfractionated heparin at a dose of 18 units $/ \mathrm{kg} /$ hour IV and use of thromboplastin time to perform dose adjustment. An MRI of the brachial plexus detected preganglionic lesions in
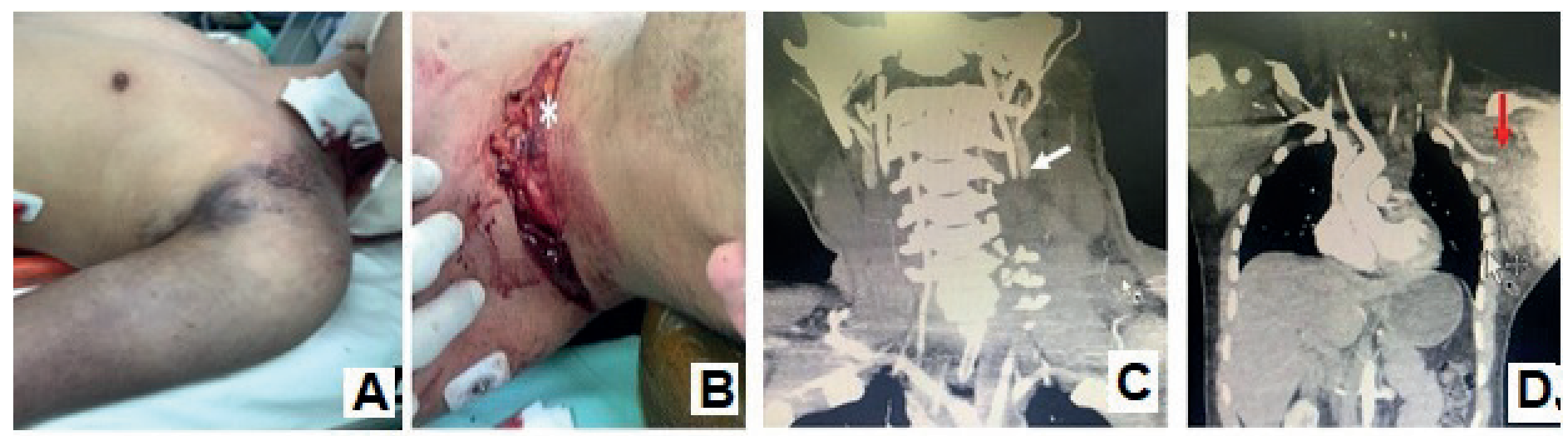

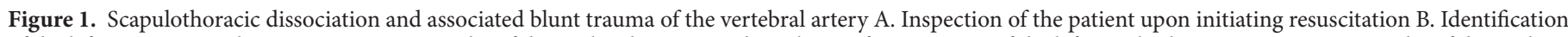
of the left zone I cervical injury B. CT angiography of the neck, white arrow, thrombosis of segment V2 of the left vertebral artery. C. CT angiography of the neck, abdomen, and chest, red arrow, complete transection of the left axillary artery, increased soft tissue density in the axillary region. 
the left C5 and C6 roots, with associated pseudomeningocele. Conservative management was initiated with deferred evaluation for the possibility of nerve reconstruction.

During the postoperative period, the patient experienced bleeding from the fasciotomy sites of the left upper limb that warranted a surgical revision with intraoperative findings of transection to the basilic vein. Ligation and exhaustive hemostasis were performed with subsequent control of bleeding.

The repeat CT scan revealed a localized thrombosis in the vertebral artery, which at that time had no major impact on postoperative course. Late secondary closure of the fasciotomies was performed.

The patient was discharged after 22 days of hospitalization managed by intensive care services, general surgery, plastic surgery, orthopedics, neurosurgery, and physical therapy. $\mathrm{He}$ demonstrated overall clinical improvement, even when there were minor cognitive memory deficits and the expected left brachial plexus injury. The patient was started on subcutaneous low molecular weight heparin $1 \mathrm{mg} / \mathrm{kg}$ every 12 hours for three months and subsequent anti-platelet therapy with $100 \mathrm{mg}$ of oral acetylsalicylic acid every 24 hours and $100 \mathrm{mg}$ of clopidogrel orally every 24 hours for six months.

Outpatient management was performed by general surgery, orthopedics, hand surgery, and physical therapy. Six months after the trauma, reconstruction of the C5-T1 left brachial plexus was performed, which resulted in a partial recovery of functionality up to the proximal third of the arm. After one year, the patient still has not considered amputation and continues with rehabilitation and follow up with hand surgery.

\section{Discussion}

The case presented combines two injuries of high morbidity and mortality, including scapulothoracic dissociation and blunt trauma to the vertebral artery. It highlights a scenario of high complexity, uncertainty, and with generally low consensus on diagnostic approaches, operative treatments, and prognosis, among others ${ }^{5}$. The factors associated with high morbidity and mortality in this patient and described in cases of scapulo-thoracic dissociation include: hypovolemic shock, compromise to multiple vascular structures within the cervico-thoracic region including the vertebral artery, differing management options, the magnitude of these injuries, and the potential complications of the trauma and its management ${ }^{1,2}$.
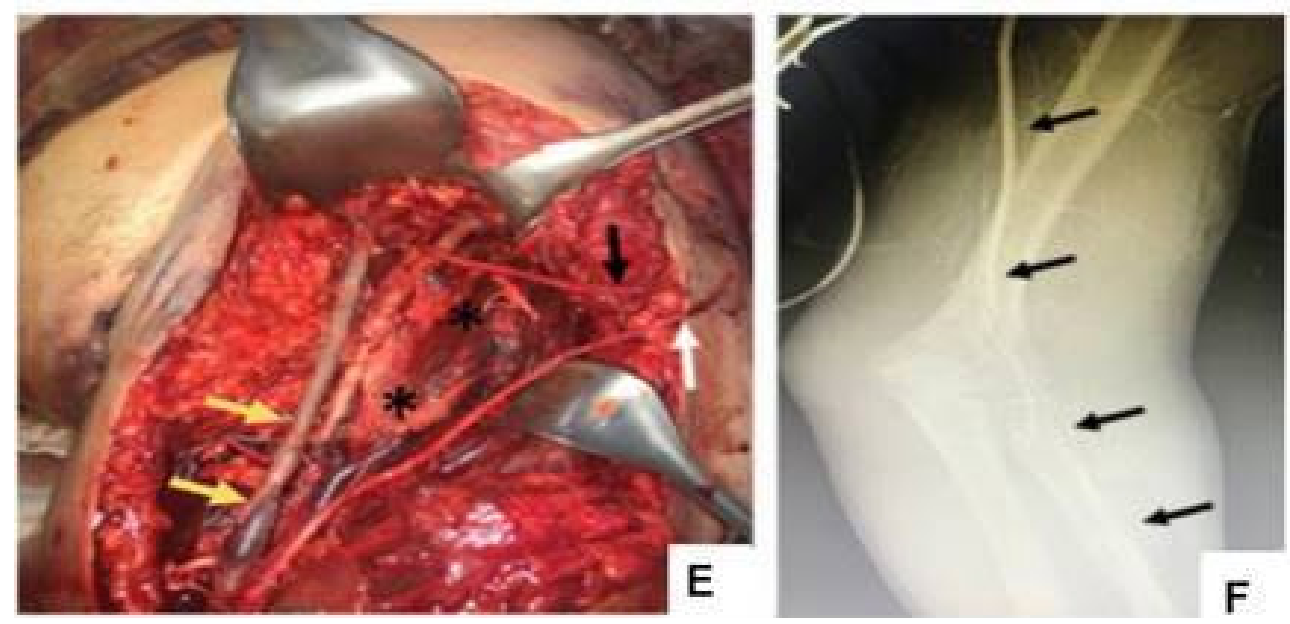

Figure 2. Scapulothoracic dissociation E. Yellow arrow, arterial reconstruction of the axillary vessels. White and black arrow, avulsed secondary trunks of the brachial plexus. F.Intraoperative arteriography with adequate contrast flow to the radial artery after vascular reconstruction. 
In regards to the complex vascular reconstructive procedure in this patient with the intention of preserving the affected limb, it could be considered a futile ${ }^{6}$ task due to the severity of the brachial plexus injuries, unfavorable functional prognosis for the limb, and the uncertainty in the effectiveness of the treatments.

The discussion focuses on the points of controversy regarding the management of the two entities in a highly complex scenario.

Preoperative diagnostic approach vs immediate surgery

A medical board was held with the two attending surgeons, the emergency medicine doctor, and the radiologist present at the institution at the time of admission. Their analysis is described in Table 1.

The blunt trauma to the vertebral artery shown on imaging did not change the surgeon's perspectives on the initial approach for the case, although it did darken the patient's prognosis at the time.

CT angiography in patients with axillo-subclavian trauma is considered within the diagnostic approach of patients with injuries secondary to blunt trauma and in scenarios of hemodynamic stability. A multicenter evaluation carried out in the USA in patients with axillo-subclavian lesions documented a mechanism of penetrating trauma in $57 \%$ of the cases and the use of CT angiography in $50 \%$ of the patients as the initial diagnostic method. In regards to treatment, $17 \%$ of the cases received endovascular therapy regardless of the mechanism of the trauma, avoiding more complex surgical procedures ${ }^{7-9}$. The authors conclude that its benefit lay in the possibility of offering concomitant endovascular management during the diagnostic procedure and thus represented an alternative to be considered in this group of patients ${ }^{10}$.

The evaluation of the case as far as the surgical board in the emergency service is concerned determines that despite the presence of indications for surgery such as traumatic cervicotomy and signs of vascular trauma to the left upper limb in this patient, the performance of a radiological evaluation by means of CT angiography prior to surgical intervention helped to determine the order and operative approach according to the location of the lesions, thus contributing to the favorable outcome of the patient.

Immediate amputation vs preservation of limb

The preservation of the left upper limb in the setting of the brachial plexus injury is a topic to analyze in this case. According to the score on the MESS scale (Mangled Extremity Severity Score) ${ }^{11}$, which assesses the prognosis of an injured limb, initial amputation would be considered in this case with $8 / 14$ points (Table 2) ${ }^{11-13}$. The intraoperative medical board discussion between surgery and orthopedics evaluated the situation and is described in Table 3.

Scores less than or equal to 6 are associated with preservation of the limb. A MESS greater than or equal to 6 is associated with a higher rate of amputation

The prognosis of a limb after a proximal neurologic injury has improved by the development of microsurgical techniques. Recent studies support conservative management even in cases of radical brachial plexus avulsion, with an early amputation rate close to $21 \%^{2,3}$. These injuries have unpredictable responses and treatment options, including amputation ${ }^{2}$ which must be individualized according to the type of injury. Post-ganglionic injuries are associated with a greater regenerative capacity when compared to pre-ganglionic injuries, which have a poor prognosis ${ }^{1,3,10,14}$. Compromise to the brachial plexus in a scapulo-thoracic dissociation has a negative influence in limb prognosis ${ }^{1}$. However, the partial effective response after reconstructive surgery and its rehabilitation, determined in this case report and according to the patient's course presented thus far, warrants consideration of a more distal level of amputation in the patient's arm. 
Table 1. Considerations for the diagnostic and therapeutic approach to scapulo-thoracic dissociation and concomitant closed vertebral artery trauma

\begin{tabular}{lll}
\hline & \multicolumn{1}{c}{ Pro's } & \multicolumn{1}{c}{ Cons } \\
\hline Immediate surgery & $\begin{array}{l}\text { Control of bleeding } \\
\text { Prompt revascularization of ischemic limb. } \\
\text { Theoretical increase in the probability of } \\
\text { survival }\end{array}$ & $\begin{array}{l}\text { Uncertainty of injury severity upon admission } \\
\text { Possibility of exsanguination and } \\
\text { intraoperative death due to irreparable vascular } \\
\text { approach. }\end{array}$ \\
\hline & $\begin{array}{l}\text { Available resource of the institutional } \\
\text { Anatomical and characterization imaging of } \\
\text { the injury and evaluation for need of initial } \\
\text { thoracotomy placement }\end{array}$ & $\begin{array}{l}\text { Loss of time in the unstable patient } \\
\text { to trauma management protocols }\end{array}$ \\
& Establish an option for endovascular management & $\begin{array}{l}\text { Complementary imaging studies are part of the } \\
\text { secondary surgery of the polytrauma patient. }\end{array}$ \\
& Initial (balloon occlusion) & \\
\hline
\end{tabular}

Similarly, the psychological impact derived from the process of acceptance and possible "programmed grief" after the exhaustion of therapeutic options, suggests better rehabilitation of an amputated limb ${ }^{15}$.

Blunt trauma to the vertebral artery

Blunt cerebrovascular trauma includes traumas of the internal carotid artery and vertebral artery, both being entities that are difficult to diagnose in a polytrauma patient and are considered determinants of late mortality ${ }^{5,16}$. Angiography technique in patients with a high risk for blunt cerebrovascular trauma (cervical hematoma, neurological deficit, high-energy trauma mechanism, subluxations or fractures of the cervical vertebrae) found an incidence of $34 \%$ of closed vertebral artery trauma ${ }^{16}$. Therefore, a possible underreporting of cases exists due to the low index of suspicion of such injuries and the care of multiple injuries in a polytrauma patient ${ }^{4}$. The importance of early detection along with early management has an impact on prognosis ${ }^{1,4,16,17}$. For this reason, in 2017 the ATLS (Advaced Trauma Life Support) incorporated diagnostic strategies for recognition of such traumas in potential candidates ${ }^{16}$. The diagnostic operative characteristics of CT angiography (sensitivity 97.7\%, specificity $100 \%$, positive predictive value $100 \%$ and negative predictive value $99.3 \%$ ), although comparable to MRI angiography, make it the study of choice due to its greater availability ${ }^{16}$.

Table 2. Modified from the Mangled Extremity Severity scale (MESS) ${ }^{11}$.

\begin{tabular}{lc} 
Mangled Extremity Severity & Points \\
\hline Skeletal / Soft tissue injury & \\
Low energy (stab wound, simple fracture, low energy gunshot wound) & 1 \\
Medium energy (open or multiple fractures, dislocation) & 2 \\
High energy (high speed motor vehicle collision or rifle bullet wound, crush injury) & 3 \\
Very high energy (the above plus large contamination, soft tissue avulsion) & 4 \\
\hline Limb ischemia* & 1 \\
Reduced or absent pulse but normal perfusion & 2 \\
No pulse paresthesia, decreased capillary filling & 3 \\
Cold, paralyzed, senseless, rigid & \\
\hline Shock & 0 \\
Systolic blood pressure $>90$ mmHg constant & 1 \\
Systolic blood pressure $<90$ mmHg transient & 2 \\
Systolic blood pressure $<90$ mmHg persistent & \\
\hline Age (years) & 0 \\
Under 30 & 1 \\
Between $30-50$ & 2 \\
\hline Over 50 &
\end{tabular}


Table 3. Considerations for left upper limb amputation as an initial approach in scapulo-thoracic dissociation

\begin{tabular}{lll}
\hline & \multicolumn{1}{c}{ Pro's } & \multicolumn{1}{c}{ Con's } \\
\hline Immediate amputation & $\begin{array}{l}\text { Control of bleeding in patients with shock and } \\
\text { complex injuries } \\
\text { Possibility of reperfusion syndrome }\end{array}$ & $\begin{array}{l}\text { Technical capabilities of the professionals involved } \\
\text { High-level institutional therapeutic support } \\
\text { Possibility of partial recovery from neurological injury, } \\
\text { wigh MESS score indicating poor limb prognosis decrease in the level of a future amputation } \\
\text { Psychological impact on the patient }\end{array}$ \\
\hline
\end{tabular}

Table 4. Classification of cerebrovascular blunt trauma (blunt trauma to the vertebral artery and blunt internal carotid artery trauma). Modified from ${ }^{11}$.

\begin{tabular}{llcc}
\hline Grade of Injury & \multicolumn{1}{c}{ Characteristics } & Rate of cerebrovascular event & Rate of mortality (\%) \\
\hline Grade I & Light compromise $<25 \%$ & 3 & 11 \\
Grade II & Light compromise $>25 \%$ & 11 & 11 \\
& Intraluminal thrombus & & \\
Grade III & Intimal tear & 33 & 11 \\
Grade IV & Pseudoaneurysm & 44 & 22 \\
Grade IV & Arterial occlusion & 100 & 100 \\
\hline
\end{tabular}

A classification suggested by angiographic patterns, of blunt cerebrovascular trauma (trauma to the internal carotid artery and vertebral artery) considers their neurological prognosis and survival ${ }^{16,17}$ is presented in Table 4 . In the present case, it corresponded to a grade $\mathrm{IV} / \mathrm{V}$, therapeutic anticoagulation was initiated in the immediate postoperative period after evaluating the risk/benefit in a complex vascular surgery with fasciotomies. The state of the art in the treatment of blunt trauma to the vertebral artery indicates use of this therapy in grade I-IV injuries, to procure control of distal thrombosis and prevention of late embolism, considering endovascular management, on a case-by-case basis.

The blunt trauma of the vertebral artery generates an additive interaction with respect to the scapulothoracic dissociation and the patient's prognosis ${ }^{18}$, which contributes to a greater deleterious effect on the organic presentation, use of resources, concomitant therapies, and limits the possibilities of success. Its presence did not affect the final cerebral and neurological recovery of the patient, which is possibly attributed to a compensation from the circulation of the circle of Willis.

It is pertinent to note that during the course of the patient's care, a permanent communication was established with the patient and his family, who expressed a feeling of gratitude and an attitude of collaboration with the medical and paramedical personnel involved in the case. Similarly, he illustrated the need to continue functional rehabilitation of the limb and about the possibility of a late amputation.

\section{Conclusion}

The case presented shows a context of high uncertainty and low probability of consensus, where decision-making must be carried out at a different level from that contemplated in daily clinical practice. Medical boards with various specialties are useful tools, in these complex scenarios, generate actions of shared responsibility, add experiences and knowledge in pursuit of a common final goal and implements teamwork as a determining factor in the outcome.

The generation of multidisciplinary cooperation in various phases of the patient's treatment contributed to the success of the case and reinforces the idea of its permanent execution for the benefit of patients, institutions, and health professionals. 


\section{Consent}

Written informed consent was obtained from the patient for the publication of this case report and accompanying images.

\section{References}

1. Choo A, Schottel P, Burgess A, Scapulothoracic dissociation. J Am Academy Orthopaedic Surg. 2017; 25(5): 339-347. Doi: 10.5435/JAAOS-D-15-00509

2. Flanagin B, Leslie M. Scapulothoracic dissociation. Orthopedic Clin North Am. 2013; 44(1): 1-7. Doi: 10.1016/j.ocl.2012.09.002

3. Zelle B, Pape H, Gerich T, Garapati R, Ceylan B, Krettek C. Functional outcome following scapulothoracic dissociation. J Bone Joint Surg-Am. 2004; 86(1):2-8. Doi: 10.2106/00004623-200401000-00002

4. Alterman D, Heidel R, Daley B, Grandas O, Stevens S, Goldman M et al. Contemporary outcomes of vertebral artery injury. J Vasc Surg. 2013;57(3):741-746. Doi: 10.1016/j.jvs.2012.09.006

5. Greenhalgh T, Plsek PE. Complexity science: the challenge of complexity in health care. BMJ. 2001; 323 : 625-628. Doi:10.1136/bmj.323.7313.625

6. Spill GR, Vente T, Frader J, Smith S, Giacino J, Zafonte R, Coppard B, et al. Futility in Rehabilitation. PM R. 2019; 11: 420-428. Doi:10.1002/pmrj.12152

7. Gagnier JJ, Kienle G, Altman DG, Moher D, Sox H, Riley D. The CARE guidelines: consensus-based clinical case reporting guideline development. Glob Adv Health Med. 2013; 2(5): 38-43.

8. Waller C, Cogbill T, Kallies K, Ramirez L, Cardenas J, Todd S, et al. Contemporary management of subclavian and axillary artery injuries -A Western Trauma Association multicenter review. J Trauma Acute Care Surg. 2017; 83(6): 1023-1031. Doi:10.1097/TA.0000000000001645

9. Akyuz M, Gokalp O, Ozcem B, Ozcan S, Besir Y, Gurbuz A. Surgical management of axillosubclavian vascular injuries. Pak J Med Sci. 2015; 31(3): 552-555. Doi:10.12669/pjms.313.7316

10. Tadayon N, Yavari N, Zarrintan S, Hosseini SM, Kalantar-Motamedi S. Management of traumatic subclavian artery injuries in a high-volume vascular surgery center in Iran. J Cardiovascular Thoracic Res. 2020; 12(2): 145-149. Doi: 10.34172/jcvtr.2020.24

11. Schirò G, Sessa S, Piccioli A, Maccauro G. Primary amputation vs limb salvage in mangled extremity: a systematic review of the current scoring system. BMC Musculoskeletal Disorders. 2015; 16(1): 372 . DOI:10.1186/s12891-015-0832-7

12. Javali RH, Krishnamoorthy, Patil A, Srinivasarangan M, Suraj, Sriharsha. Comparison of injury severity score, new injury severity score, revised trauma score and trauma and injury severity score for mortality prediction in elderly trauma patients. Indian J Critical Care Med. 2019; 23(2): 73-77. Doi: 10.5005/jpjournals-10071-23120

13. Johansen K, Daines M, Howey T, Helfet D, Hansen ST Jr. Objective criteria accurately predict amputation following lower extremity trauma. J Trauma. 1990;30(5):568-573. doi:10.1097/00005373-199005000-00007

14. Masmejean E, Asfazadourian $\mathrm{H}$, Alnot J. Brachial plexus injuries in scapulothoracic dissociation. J Hand Surg. 2000;25(4):336-340. DOI:10.1054/jhsb.2000.0393 
15. Siqueira M, Martins R, Heise C, Foroni L. Elective amputation of the upper limb is an option in the treatment of traumatic injuries of the brachial plexus? Arquivos de Neuro-Psiquiatria. 2017;75(9):667-670. DOI: 10.1590/0004-282x20170096

16. Shafafy R, Suresh S, Afolayan J, Vaccaro A, Panchmatia J. Blunt vertebral vascular injury in trauma patients: ATLS(r) recommendations and review of current evidence. J Spine Surg. 2017;3(2):217-225. DOI: 10.21037/jss.2017.05.10

17. Biffl W, Moore E, Ryu R, Offner P, Novak Z, Coldwell D et al. The Unrecognized epidemic of blunt carotid arterial injuries. Ann Surg. 1998;228(4):462-470. DOI: 10.1097/00000658-199810000-00003

18. de Irala J, Martínez-González M, Guillén GF. ¿Qué es una variable modificadora del efecto?. Medicina Clínica. 2001;117(8):297-302. DOI:10.1016/S0025-7753(01)72092-1 